Discussion Papers

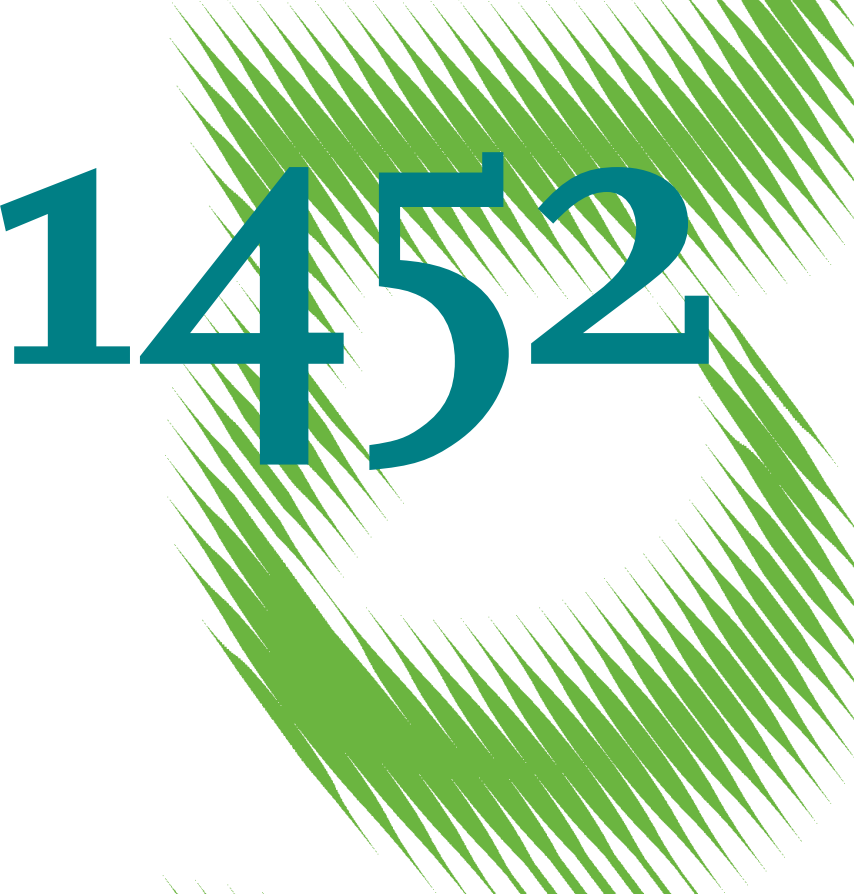

Renewable Energy Support in Germany

Surcharge Development and the Impact of a Decentralized Capacity Mechanism 
Opinions expressed in this paper are those of the author(s) and do not necessarily reflect views of the institute.

IMPRESSUM

(C) DIW Berlin, 2015

DIW Berlin

German Institute for Economic Research

Mohrenstr. 58

10117 Berlin

Tel. +49 (30) $89789-0$

Fax +49 (30) $89789-200$

http://www.diw.de

ISSN electronic edition 1619-4535

Papers can be downloaded free of charge from the DIW Berlin website:

http://www.diw.de/discussionpapers

Discussion Papers of DIW Berlin are indexed in RePEc and SSRN:

http://ideas.repec.org/s/diw/diwwpp.html

http://www.ssrn.com/link/DIW-Berlin-German-Inst-Econ-Res.html 


\title{
Renewable Energy Support in Germany: Surcharge Development and the Impact of a Decentralized Capacity Mechanism $^{1}$
}

\author{
Thure Traber ${ }^{2}$ and Claudia Kemfert ${ }^{3}$
}

\begin{abstract}
The German support for renewable energies in the electricity sector is based on the feed-in tariff for investors that grants guaranteed revenues for their renewable energy supply. Corresponding to differences of granted tariffs and respective market values, a surcharge on consumption covers differential costs. While granted tariffs are bound to fall with advances in renewable energy technologies, the market design and the flexibility of the system influence the expected market values of renewables and the necessary surcharge. We apply the European electricity market equilibrium model EMELIE-ESY to investigate this relationship.

We find a crucial dependence of market values of renewables on a high system flexibility and the current so-called energy-only market design. Under these conditions, the market values of renewables sequentially recover with increasing market prices by 2024 and 2034. This allows to limit the increase of the core surcharge to below a quarter of its 2013 value by 2024 despite a doubling of renewables, and to introduce substantial surcharge reductions through 2034. However, the introduction of a capacity market would erode market values of renewable energies and induce a pronounced growth of the core surcharge. Under inflexible supply structures and a capacity market, we find an increase of the core surcharge of more than 50 percent by 2024, a respective loss of the market value of wind power of the same magnitude, and an increase of the generation induced part of the consumer prices of more than a quarter.
\end{abstract}

JEL classification: C63; D47; D61

Keywords: electricity market; renewable energy support; capacity mechanism

\footnotetext{
${ }^{1}$ Financial support by the Mercator foundation is gratefully acknowledged.

${ }^{2}$ Corresponding author; DIW Econ Berlin, Mohrenstr. 58, D-10117 Berlin, Germany; Email: ttraber@diw-econ.de,Tel: +49 302060972 23, Fax: +49 30 2060972-99

${ }^{3}$ German Institute for Economic Research (DIW Berlin) and Hertie School of Governance.
} 


\section{Introduction}

After the successful first phase of the Energiewende, the work horse regulation for the support of renewable electricity supply in Germany, the EEG, is discussed under a variety of aspects. First, the surcharge system leads to a limitation of the coupling of consumer prices with market prices because higher wholesale prices induce lower necessary surcharges and vice versa. Secondly, since exports from Germany to its neighbors are not charged with renewable energy support costs, the so-called merit-order effect of renewable energy feed-in dampens wholesale electricity prices and induces an increase of net-exports of Germany. This leads to an only partial substitution of the use of conventional sources by increased renewable electricity generation, and to a less than proportional emission reduction (Traber and Kemfert (2011)). Consequently, German climate targets for the electricity sector are unlikely to be reached by the actual renewable energy support alone. Finally, exemptions from the surcharge that finances the support mechanism are granted to increasing parts of industrial consumption in order to protect the production of energy intensive goods from international competition. This practice is questioned by amongst others the competition authorities of the European Commission.

Against this background, the introduction of a mechanism similar to the capacity certificate system scheduled by the French regulator is also considered for Germany. To ensure adequate system reliability, such a capacity mechanism would impact international trade and potentially the surcharge in Germany. Since the system of capacity certificates influences the market values of renewables, the differences between guaranteed feed-in tariffs and market values are likely to change as well. In turn, the necessary EEG financing charge is likely to grow and potentially exacerbate the aforementioned problems. At the same time, the further transition towards a renewable energy based electricity system enjoys a broad political consensus in Germany and the share of renewable energy in overall electricity supply is planned to reach at least 40 percent by 2025 .

For the assessment of these developments, two streams of literature are of particular relevance. The first stream concerns the so called merit-order effect of renewable energy supply, while the second comprises work on the market value of renewable energy. Both topics have been assessed for a variety of countries. The majority of studies, as well as the following review focuses on the case of Germany.

Most of the literature on the German merit-order effect conducts ex post analysis. Sensfuß et al. (2008) use an agent-based simulation approach which accounts for start-up costs, and analyze effects of wind power support on market prices. They find price reducing effects of about 0.7 Cent due to 52.2 TWh renewable energy supply for Germany in 2006. Rathmann (2007) assesses the support of renewable energy by using a numerical model with varying assumptions on conventional generation costs which are based on historic fuel price and emission market price data. He finds that renewable energy support may reduce electricity wholesale prices for a range of parameter values. Bode and Groscurth (2006) use a similar model of the German power sector and demonstrate the possibility of price reducing effects for consumers 
if they are at least partially exempted from the burden of the renewable energy supply (RES) support. Traber and Kemfert (2009) apply an oligopolistic European market model which endogenously calculates emission prices and the differential costs of RES support. Significant feedbacks of the emission market are found since the roll-out of renewable energy reduces the emission market prices, conventional production costs and overall prices.

Only limited work deals with the simulation of the development of the future merit-order effect. Exceptions are given by Nicolosi (2012), Traber and Kemfert (2011) and Fürsch et al. (2012). These studies find price reductions due to renewables of about five to ten percent of wholesale spot prices, i.e. about three to four Euro per MWh by 2020. Studies on other countries or regions are carried out for example by Jonsson et al. (2010), Munksgaard and Morthorst (2008) with meritorder effects in Denmark, O'Mahoney and Denny (2011) on the Irish pool market, and Bushnell (2010) on US markets. Although market conditions vary quite substantially across these regions, reported relative merit-order effects of these studies are around five and ten percent of average market prices and are, thus, comparable to those found in the studies for Germany.

The merit-order effect feeds back to reduce the market values of the fluctuating renewable energies with low marginal costs. This effect is especially relevant under extreme situations which have to be modeled with a high temporal resolution and broad coverage of load situations or a probabilistic approach to capture extrema. Nicolosi (2012) uses a model that features a high temporal resolution, and includes adjacent markets surrounding Germany to compute a cost minimizing dispatch and investment given assumed consumption developments until 2030. He also calculates the value of renewable energy supply under a variety of possible scenarios, and finds system values in Germany for wind onshore and solar electricity of between 80 and 70 percent under penetration rates of around 34 and 10 percent respectively. In a recent study Hirth (2013) introduces a similar cost minimization program with high temporal resolution and a variety of scenarios characterized by the availability of flexibility options. He finds comparably low system values of wind that drop as low as 50 percent of average electricity values if market shares of wind approach 30 percent. Both studies stress the importance of flexibility options for the possibilities to integrate and market fluctuating renewable energy sources, i.e. reducing the mustrun of combined heat and power (CHP), increasing external trade connections, and introducing pump storage. However, flexibility of consumption in form of demand side response and demand side management, the interplay with impacts on changing support costs, and the potential impact of capacity mechanisms is not considered in previous work.

This gap in the analysis is filled with a model of the central European electricity market, i.e. Germany, its physically connected neighbors, and Italy. After the analytical description of the model and its calibration for the replication of wholesale market prices and international trade flows, we show results for two regulatory settings combined with three flexibility scenarios. In the inflexible scenario we assume an inelastic supply from windmills and a must-run of CHP plants. Furthermore, we simulate the impact of an revenue optimizing operation of wind energy in the 
second scenario, and finally drop additionally the must-run restriction for CHP in the third scenario.

We find a crucial dependency of the market value of wind energy on the flexibility setting and the capacity market policy. Under highly inflexible supply combined with a capacity market policy, the value of wind energy in 2024 is 60 percent lower than under energy-only market regulation with high flexibility: Wind power receives between 15 and 37 Euro per MWh depending on the scenario. Consequently, the differential costs and the necessary surcharge for renewable energy support is also significantly impacted by the policy framework. Under flexibility the surcharge can be about 20 percent lower than under a capacity mechanism with inflexible supply. In that case, the necessary surcharge increase can be limited to about a quarter of today's value. Perspectively, the surcharge can furthermore decrease drastically towards 2034 since market values of renewables may recover while their tariffs are bound to decrease rapidly. Assuming flexible supplies by 2034 we find a surcharge of around 20 Euro per MWh at wholesale prices between 57 and 59 Euro per MWh. These findings are contrasting results from earlier studies, which report market values of renewables that are monotonously falling with increasing fluctuating renewables.

\section{Model and Refinements}

We base our model development on the existing framework for the long-term perspective of the European wholesale electricity market called EMELIE-ESY as laid out in Schröder et al. (2013), and implement a capacity module (Capmod) with stochastic load events and a capacity mechanism as described in Traber (2014). Furthermore, we include the German feed-in tariff financed by a renewable energy surcharge on final consumption.

The model is a partial equilibrium model that integrates multi-period plant dispatch and investment decisions. The main variables are wholesale prices for electricity, conventional production and demand patterns as well as investments into thermal generation capacity. In addition, for the simulation of the German support system, we endogenously calculate a surcharge levied on German consumption that finances the difference between guaranteed feed-in tariffs for renewable energy supply and their market value, i.e. the EEG differential costs. Different from other studies, we also take responses of demand on surcharge changes into account.

Moreover, to facilitate the analysis of capacity policy impacts, a capacity market is simulated. The considered mechanism relies on the obligation of supply to hold five percent reliable capacity or equivalent tradable capacity certificates relative to their peak supply. This mechanism creates capacity prices that reflect on the one hand the opportunity costs of foregone energy market revenues if capacity is sold as reserve, and, on the other hand either costs of new investments or the marginal willingness to pay for electricity in equilibrium.

The supply of conventional units is modeled as generally market driven, i.e. a 
conventional unit supplies electricity if the market prices cover fuel, emission operation and maintenance, as well as depreciation costs incurred due to generation and ramp-up of units. However, we also include demand for the combined production of heat and power. Additionally, we model the option to curtail wind energy if its market value net of capacity certificate cost is negative.

In the following, we firstly introduce the model for the simulation of the energyonly market with power generation and plant investment of generators acting on a domestic market. Secondly, we lay out the module for the representation of international trade, which integrates the national markets. The two components constitute the basic energy-only market model. Furthermore, we present the module for a capacity mechanism that is based on the requirement of generators to hold reliable capacity in relation to their peak load supply. Finally, we introduce the functional forms of costs and demand and present the implementation of the surcharge for renewable energy in the model.

\subsection{Basic model}

Generators are represented by technology classes and are assumed to behave perfectly competitive and, in addition, to have perfect foresight. In particular, they perfectly assign frequencies $f(\omega)$ to demand and wind events denoted $\omega$. We aggregate generators of each country $s$ to a single representative national power plant fleet. The time horizon consists of single periods $y$, each comprising of a number of time steps $t$, with inverse demand denoted $P^{s, y, t, \omega}\left(X^{s, y, t, \omega}\right)$, and $X^{s, y, t, \omega}$ total consumption. Furthermore, we assume linear variable costs of ramped up capacity $C_{q}^{s, y, n}$, and linear ramping costs with $C_{l}^{y, n}$ of technologies $n$. Fixed cost accrue proportional to investments $k$ and are denoted $F^{n}$.

The restricted optimization problem of a country $s$ regarding generation $q$, ramping $l$, and investment $k$ can be written as the following Karush-Kuhn-Tucker Lagrangian:

$$
\begin{aligned}
\max _{q, l, k} L^{s}= & \sum_{y=1}^{Y}\left(\frac{1}{1+\delta}\right)^{y} \sum_{n=1}^{N} \sum_{t=1}^{T} \sum_{\omega=1}^{\Omega}\left(f ( \omega ) \left(P^{s, y, t, \omega}\left(X^{s, y, t, \omega}\right) q^{s, y, n, t, \omega}\right.\right. \\
& -C_{q}^{s, y, n} q^{s, y, n, t, \omega}-C_{l}^{y, n} l^{s, y, n, t, \omega} \\
& +\lambda^{s, y, n, t, \omega}\left(\bar{l}^{n}\left(k_{0}^{s, y, n}+\sum_{z=1}^{y} k^{s, z, n}\right) a^{s, n, t, \omega}-l^{s, y, n, t, \omega}\right) \\
& +\rho^{s, y, n, t, \omega}\left(l^{s, y, n, t, \omega}-q^{s, y, n, t, \omega}+q^{s, y, n, t-1, \omega}\right) \\
& \left.+\kappa^{s, y, n, t, \omega}\left(\left(k_{0}^{s, y, n}+\sum_{z=1}^{y} k^{s, z, n}\right) a^{s, n, t, \omega}-q^{s, y, n, t, \omega}\right)\right) \\
& \left.+\iota^{s, y, n}\left(\bar{k}^{s, y, n}-k^{s, y, n}\right)-F^{n} k^{s, y, n}\right)
\end{aligned}
$$

where $k_{0}, a$, and $\bar{l}$ denote existing capacity, plant availability and maximum relative load gradient respectively. (1) is simply the sum of energy market revenues net of 
variable generation costs, ramping costs, and investments discounted to net present values. This sum is restricted by maximum load gradients, minimum ramping requirements, maximum generation capacity, and maximum investment, reflected by their respective shadow variables ${ }^{4} \lambda, \rho, \kappa$, and $\iota$.

By derivation of the Lagrangian with respect to supply and ramping, we first introduce the optimization of generation of existing technologies. We distinguish between thermal technologies, which are assumed to have a constant availability over the year, and fluctuating renewable energies, which have availabilities that are allowed to vary over the time-steps of a day, and between seasonal events. Furthermore, renewables are assumed to have no variable costs, and are only restricted by their availabilities and their exogenous capacity development.

The first order conditions of firm $i$ with regard to conventional supply can be described as two corresponding sets of equations. Since we intent to model a sequence of reference days with identical demand conditions, we introduce the convention that the last time step of the day is followed by the first.

The first order conditions for the first 23 time steps are written as:

$$
\begin{gathered}
\frac{\partial L^{s}}{\partial q^{s, y, n, t, \omega}}=\quad P^{s, y, t, \omega}\left(X^{s, y, t, \omega}\right)-C_{q}^{s, y, n}-\rho^{s, y, n, t, \omega}+\rho^{s, y, n, t+1, \omega}-\kappa^{s, y, n, t, \omega} \leq 0, \\
\forall y \in Y, n \in N, 0<t<24, \omega \in \Omega .
\end{gathered}
$$

Correspondingly, for $t=24$ we have:

$$
\begin{gathered}
\frac{\partial L^{s}}{\partial q^{s, y, n, t, \omega}}=\quad P^{s, y, t, \omega}\left(X^{s, y, t, \omega}\right)-C_{q}^{s, y, n}-\rho^{s, y, n, t, \omega}+\rho^{s, y, n, 1, \omega}-\kappa^{s, y, n, t, \omega} \leq 0, \\
\forall y \in Y, n \in N, t=24, \omega \in \Omega .
\end{gathered}
$$

The supply optimality conditions reflect perfectly competitive firm behavior under capacity and ramping restrictions, i.e. the shadow values of the capacity restriction $\kappa$ are equal to marginal profits net of marginal ramping costs. The latter includes potentially reduced marginal ramping costs of the following time step.

The first order conditions with regard to ramping yields

$$
\begin{aligned}
\frac{\partial L^{s}}{\partial l^{s, y, n, t, \omega}}=\quad & \rho^{s, y, n, t, \omega}-C_{l}^{y, n}-\lambda^{s, y, n, t, \omega} \leq 0, \\
& \forall y \in Y, n \in N, t=24, \omega \in \Omega,
\end{aligned}
$$

which says that the shadow value of a marginally ramped-up unit has to cover the ramping costs, and additionally the shadow value of the ramping restriction, in case of maximum ramping.

\footnotetext{
${ }^{4}$ The model notation is listed at the end of the document.
} 
In case of fluctuating renewable energies (2) and (3) reduce to

$$
\begin{gathered}
\frac{\partial L^{s}}{\partial q^{s, y, n, t, \omega}}=\quad P^{s, y, t, \omega}\left(X^{s, y, t, \omega}\right)-\kappa^{s, y, n, t, \omega} \leq 0, \\
\forall y \in Y, n \in N, t \in T, \omega \in \Omega
\end{gathered}
$$

with the market price $P$ dropping in case of a remuneration by the fixed feed-in tariff. It follows from (5) that the renewable energy source is fully utilized unless the market price is negative, while at negative prices renewables are curtailed. In contrast, renewables are fully utilized under feed-in tariffs. Similarly, the generation of CHP is supplied inelastically until the exogenous heat demand is satisfied. Corresponding electricity output is deducted on the one hand from demand and on the other hand from the capacity limit of the respective units.

We now turn to the problem of optimal investment. The following first order conditions relate marginal profits to investment costs and define the optimal investment decisions of firm $i$ :

$$
\begin{aligned}
\frac{\partial L^{s}}{\partial k^{s, y, n}}= & \sum_{z=y}^{Y}\left(\frac{1}{1+\delta}\right)^{z} \sum_{t=1}^{T} \sum_{\omega=1}^{\Omega}\left(f(\omega)\left(\kappa^{s, z, t, n, \omega}+\bar{l}^{n} \lambda^{s, z, t, n, \omega}\right) a^{s, n, t, \omega}-\iota^{s, y, n}\right) \\
& -F^{n} \leq 0, \forall y \in Y, n \in N .
\end{aligned}
$$

Equation (6) essentially says that investment is increased up to its restriction if the net present value of the relaxation of the capacity and load gradient restrictions is greater than fixed costs $F^{n}$.

Furthermore, the optimization variables are restricted to be non-negative, and hold with equality if they are greater than zero:

$$
q \geq 0, k \geq 0, q \frac{\partial L}{\partial q}=0, k \frac{\partial L}{\partial k}=0 .
$$

Similar conditions also apply to the shadow variables and corresponding restrictions:

$$
\kappa \geq 0, \iota \geq 0, \frac{\partial L}{\partial \kappa} \geq 0, \kappa \frac{\partial L}{\partial \kappa}=0, \iota \frac{\partial L}{\partial \iota} \geq 0, \iota \frac{\partial L}{\partial \iota}=0 .
$$

The market clearing conditions integrate national markets and are written as:

$$
\begin{array}{r}
X^{s, y, t, \omega}\left(P^{s, y, t, \omega}\right)=\sum_{n}^{N} q^{s, y, n, t, \omega}-\sum_{\substack{s s \neq s\\
}}\left(E x^{s, s s, y, t, \omega}-E x^{s s, s, y, t, \omega}\right), \\
\forall s \in S, y \in Y, t \in T, \omega \in \Omega,
\end{array}
$$

where the left hand side of (9) is the demand function, ss denotes a country other than $s$, and $E x^{s, s s, y, t, \omega}$ denotes an export from country $s$ to country $s s$.

The optimization of trade flows is represented by the following first order condi- 
tion of traders ${ }^{5}$. More precisely, exports of electricity from region $s$ to region ss are optimized by the following optimality conditions of a representative trader:

$$
\begin{aligned}
& \frac{\partial \pi}{\partial E x^{s, s s, y, t, \omega}}=P^{s s, y, t, \omega}\left(X^{s s, y, t, \omega}\right)-P^{s, y, t, \omega}\left(X^{s, y, t, \omega}\right)-\tau^{s, s s, y, t, \omega} \leq 0, \\
& \forall s, s s \in S, y \in Y, t \in T, \omega \in \Omega,
\end{aligned}
$$

where $E x^{s, s s, y, t, \omega}$ denotes electricity exports from country $s$ to the country of destination $s s$, and $\tau^{s, s s, y, t, \omega}$ is the (scarcity) price of transmission capacity from region $s$ to $s s$, implied by the restricted maximum transmission line capacity. Furthermore, optimality requires

$$
\frac{\partial \pi}{\partial \tau} \geq 0, \tau \geq 0, \tau \frac{\partial \pi}{\partial \tau}=0
$$

In conjunction with (11), (10) says that in case of exports the prices of the import country have to cover the prices of the export country plus the shadow price of transmission capacity.

\subsection{Model with capacity mechanism}

The capacity mechanism (CM) modeled in this paper is based on a decentralized regulation with reserve obligations prescribed by the regulator to guarantee firm capacity that establishes a reserve factor in relation to peak supply. Each technology is free to fulfill its capacity obligation either by less than maximum supply during peak load hours or through the purchase of certified idle capacity from other technologies. In case technologies have different opportunity costs to fulfill their obligation, the regulation induces a market for certified firm capacity with market clearing certificate prices $\mu$. These are induced by the following inequality restrictions:

$$
\begin{array}{r}
\bar{\alpha}\left(\sum_{n} q^{s, y, n, t, \omega}+E x^{s, s s, y, t, \omega}-E x^{s s, s, y, t, \omega}\right) \leq \sum_{n}\left(k_{0}^{s, y, n}+\sum_{z=1}^{y} k^{s, z, n}\right) \bar{a}^{n}, \\
\forall y \in Y, t \in T, \omega \in \Omega,
\end{array}
$$

which requires that supplies multiplied by a fixed reserve factor $\bar{\alpha}$ on the left hand side of (12) are at least covered by firm capacities collected on the right hand side, with $\bar{a}$ denoting the firm availability factor.

\footnotetext{
${ }^{5}$ The corresponding optimization problem is taken from Traber (2014).
} 


$$
\begin{aligned}
\max _{q, l, k} L^{s}= & \sum_{y=1}^{Y}\left(\frac{1}{1+\delta}\right)^{y} \sum_{n=1}^{N} \sum_{t=1}^{T} \sum_{\omega=1}^{\Omega}\left(f ( \omega ) \left(P^{s, y, t, \omega}\left(X^{s, y, t, \omega}\right) q^{s, y, n, t, \omega}\right.\right. \\
& -C_{q}^{s, y, n} q^{s, y, n, t, \omega}-C_{l}^{y, n} l^{s, y, n, t, \omega} \\
& +\bar{\alpha} \mu^{s, y, t, \omega}\left(\sum_{n}\left(k_{0}^{s, y, n}+\sum_{z=1}^{y} k^{s, z, n}\right)-q^{s, y, n, t, \omega}\right) \\
& +\lambda^{s, y, n, t, \omega}\left(\bar{l}^{n}\left(k_{0}^{s, y, n}+\sum_{z=1}^{y} k^{s, z, n}\right) a^{s, n, t, \omega}-l^{s, y, n, t, \omega}\right) \\
& +\rho^{s, y, n, t, \omega}\left(l^{s, y, n, t, \omega}-q^{s, y, n, t, \omega}+q^{s, y, n, t-1, \omega}\right) \\
& \left.+\kappa^{s, y, n, t, \omega}\left(\left(k_{0}^{s, y, n}+\sum_{z=1}^{y} k^{s, z, n}\right) a^{s, n, t, \omega}-q^{s, y, n, t, \omega}\right)\right) \\
& \left.+\iota^{s, y, n}\left(\bar{k}^{s, y, n}-k^{s, y, n}\right)-F^{n} k^{s, y, n}\right),
\end{aligned}
$$

Deriving the KKT conditions of this problem with regard to supply we get:

$$
\begin{array}{r}
\frac{\partial L^{s}}{\partial q^{s, y, n, t, \omega}}=P^{s, y, t, \omega}\left(X^{s, y, t, \omega}\right)-C_{q}^{s, y, n}-\bar{\alpha} \mu^{s, y, t, \omega}-\kappa^{s, y, n, t, \omega} \leq 0, \\
\forall y \in Y, n \in N, t \in T, \omega \in \Omega .
\end{array}
$$

Compared to the corresponding first order conditions of the basic model, (14) shows that the capacity certificate market induces an opportunity cost component $\bar{\alpha} \mu$ to electricity supply that captures the foregone revenues from supply of idle firm capacity to the capacity trading system.

The KKT first order conditions with regard to investment can be written as

$$
\begin{aligned}
\frac{\partial L^{s}}{\partial k^{s, y, n}}= & \sum_{z=y}^{Y}\left(\frac{1}{1+\delta}\right)^{z} \sum_{t=1}^{T} \sum_{\omega=1}^{\Omega}\left(f(\omega)\left(\kappa^{s, z, t, n, \omega}+\mu^{s, z, t, \omega}+\bar{l}^{n} \lambda^{s, z, t, n, \omega}\right) a^{s, n, t, \omega}-\iota^{s, z, n}\right) \\
& -F^{n} \leq 0, \forall y \in Y, n \in N
\end{aligned}
$$

which say that investment in capacity is remunerated by additional revenues induced by the option to sell firm capacity.

Moreover, the following conditions have to hold: $\frac{\partial L}{\mu} \geq 0, \mu \geq 0$, and $\mu \frac{\partial L}{\mu}=0$.

Finally, optimal trade flows under this capacity certificate regime are based on prices net of certificate costs. For all $s, s s$ the prices $P^{s, y, t, \omega}$ in (10) are replaced by $P_{\text {prod }}^{s, y, t, \omega}=P^{s, y, t, \omega}-\mu^{s, y, t, \omega} \bar{\alpha}$. Thus, we assume that exports are not burdened by the capacity certificate prices of the country of origin. 


\subsection{Generation cost function, demand side and renewables surcharge}

The variable generation costs are separated into an energy related and a ramping related part. Energy related variable unit costs are constant in output $q$ in each period and include payments for emission allowances. They write:

$$
C_{q}^{s, y, n}=\frac{p^{s, y, n}+\phi^{y} e^{n}}{\eta^{n}}+o c^{n},
$$

where $\phi^{y}$ denotes the periodic emissions price, and $p^{y, n}, e^{n}, \eta^{n}$ and $o c^{n}$ denote the periodic fuel price, the specific fuel emission, the degree of efficiency, and the unit operation and maintenance costs of technology $n$ respectively.

Costs arising from the ramp-up of units comprise costs for the ramp-up related fuel requirement $r f^{n}$ and the costs induced by increased depreciation $d^{n}$ due to ramping processes as follows:

$$
C_{l}^{s, y, n}=r f^{n}\left(p^{s, y, n}+\phi^{y} e^{n}\right)+d^{n} .
$$

Demand is assumed to depend linearly on prices according to the elasticity of demand $\epsilon$ and is represented by the following demand function:

$$
X^{s, y, t, \omega}\left(P^{s, y, t, \omega}\right)=X 0^{s, y, t, \omega}\left(1+|\epsilon|\left(1-\frac{P^{s, y, t, \omega}}{P 0^{s, y, t, \omega}}\right)\right),
$$

where $X 0$,and $P 0$ denote the reference values for consumption and prices.

For the simulation of the German support system, we model a surcharge $\xi$ levied on consumption that finances the differences between guaranteed remuneration based on fixed feed-in tariffs $\zeta$ for renewable energy supply and their market value. Denoting supported technologies with $n^{*}$, the surcharge is calculated as:

$$
\xi^{s, y}=\frac{\sum_{n^{*} \in N} \sum_{t=1}^{T} \sum_{\omega=1}^{\Omega}\left(\zeta^{s, n^{*}}-P^{s, y, t, \omega}\right) q^{s, y, n^{*}, t, \omega}}{\sum_{t=1}^{T} \sum_{\omega=1}^{\Omega} \bar{\beta} X^{s, y, t, \omega}},
$$

where the nominator sums up the difference costs for all supported technologies, time steps and events in a year, and the denominator is the annually non-privileged consumption of a country, i.e. annual country consumption multiplied by the share of non-priviliged consumption ${ }^{6} \bar{\beta}$. The surcharge is levied on consumption and introduces a gap between wholesale and consumer prices. Modified demand cum surcharge is written as:

$$
X^{s, y, t, \omega}\left(P^{s, y, t, \omega}\right)=X 0^{s, y, t, \omega}\left(1+|\epsilon|\left(1-\frac{P^{s, y, t, \omega}+\xi^{s, y}}{P 0^{s, y, t, \omega}+\xi_{0}^{s, y}}\right)\right) .
$$

\footnotetext{
${ }^{6}$ The model is solely applied for the German surcharge, where $\bar{\beta}$ is kept constant at 74 percent. This value was officially used for the calculation of the surcharge for the year 2012. For the simulation we abstract from a possible change of this fraction. The remaining 26 percent of consumption are exempted from payment of the surcharge by assumption.
} 
Here we introduced the reference surcharge $\xi_{0}$ for the calibration of the model.

\section{Data}

The input for the model consists of reference demand levels, reference price levels, the roll-out and availability profiles of renewable energies, conventional production capacities and their generation costs. The latter are based on plant efficiencies, fuel and emission prices as well as ramping costs.

Conventional thermal electricity generation is represented by coal, gas, uranium and oil fired units with a technological disaggregation of gas and oil fired units into combined cycle gas turbines, single cycle gas turbines, and steam turbines. Existing conventional units are accessed on the basis of Platts power plant database 2011 and own refinements, and are decommissioned according to their technical life expectancy, i.e. after 50 years for steam turbine plants and after 40 years in case of gas turbines. Figure 1 documents the conventional thermal production capacities in

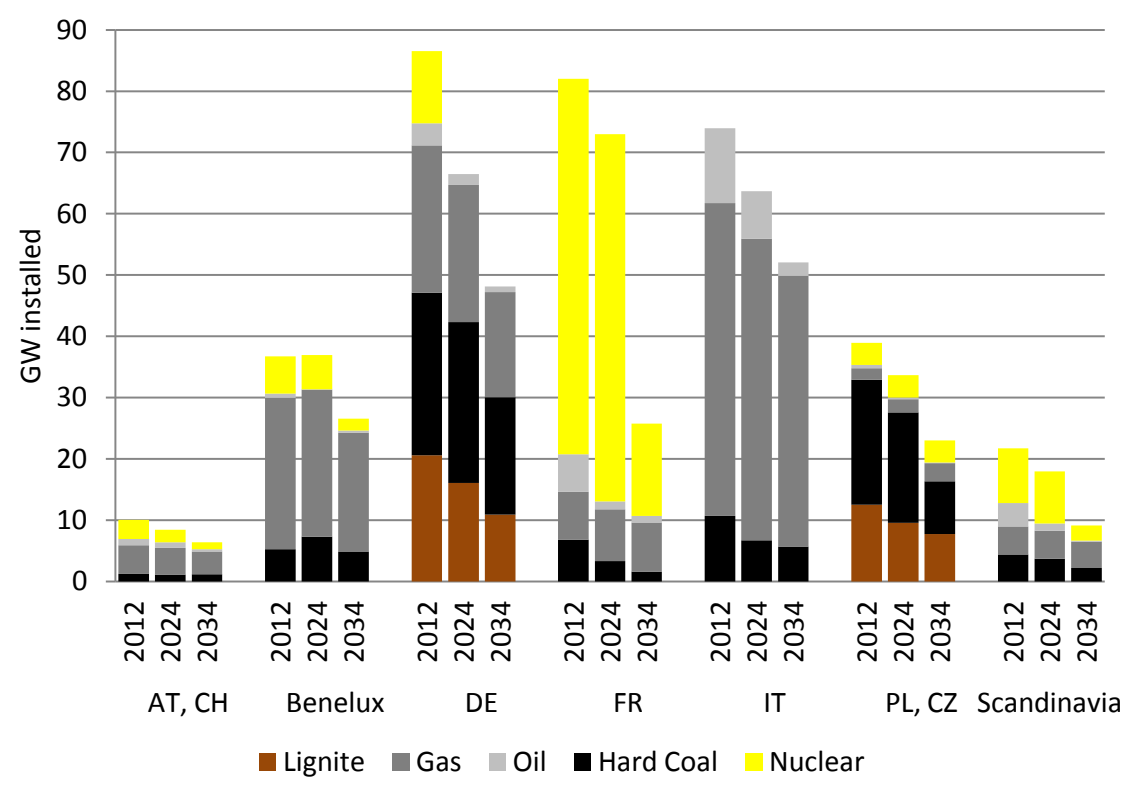

Figure 1: Conventional thermal generation capacities in 2012, 2024 and 2034.

2012, 2024 and 2034 broken down by countries and technologies used in the model. With 16.1 GW installed capacity of lignite and 26.3 GW of hard coal by 2024, coal fired power plants keep a dominant position in the aging German conventional power plant fleet over the next decades. However, the remaining amount of old coal fired units is sharply diminishing by 2034 (lignite: $10.9 \mathrm{GW}$, hard coal: $26.3 \mathrm{GW}$ ). This result is in line with the draft of the German grid development plan (NEP) ${ }^{7}$, and

\footnotetext{
${ }^{7}$ Grid Development Plan 2014, first draft, URL: http://www.netzentwicklungsplan.de/en/
} 
corresponds closely to its scenario B. For 2024 it predicts a pronounced reduction of lignite fired power plants and an almost stable capacity of hard coal fired power plants in comparison to the reference year 2012 .

In contrast to France, where installed capacity of nuclear power amounts to 59.9 GW in 2024 and still 15.1 GW in 2034, in Germany there will be no nuclear capacity installed in the upcoming decades. This is due to the German nuclear phase-out pursued by the German government in context of the Energiewende. In all countries, these existing conventional generation capacities could be complemented with limited retrofit investment into aging gas and oil fired units, and unrestricted investment into new conventional single cycle and combined cycle gas turbines.

Country specific efficiency degrees for fossil fuel fired power plants are estimated based on average national power plant age, assuming efficiency developments as proposed in Egerer et al. (2014). Figure 2 shows the derived parameters used for 2024 , and the variation in efficiency degrees induced by different average power plant age in the countries. Similarly, availability of hydro power varies considerably by country with only 23 percent annual availability in Czech Republic and 53 percent in Austria and Germany.

\begin{tabular}{|c|c|c|c|c|c|c|c|}
\hline & $\begin{array}{l}\text { Efficiency } \\
2024 \\
n^{n} \\
\\
\\
\\
{[\%]}\end{array}$ & $\begin{array}{l}\text { Variable } \\
\text { O\&M costs } \\
o c^{n} \\
{[€ / \mathrm{MWh}]}\end{array}$ & $\left|\begin{array}{l}\text { Ramping } \\
\text { fuel warm } \\
\text { start } \\
r f^{n} \\
{[\mathrm{MWh} / \mathrm{MW}]}\end{array}\right|$ & \begin{tabular}{|l} 
Ramping de- \\
preciation \\
warm start \\
$d^{n}$ \\
\\
{$[€ / \mathrm{MW}]$}
\end{tabular} & $\begin{array}{l}\text { Maximum } \\
\text { gradient } \\
I^{n} \\
{[\% / \text { hour }]}\end{array}$ & $\mid \begin{array}{l}\text { Availability } \\
a^{n}\end{array}$ & $\mid \begin{array}{l}\text { Investment \& } \\
\text { fixed O\&M } \\
\text { Costs } \\
F^{n} \\
{\left[\text { Tsd } € / \mathrm{MW}_{\mathrm{el}}\right]}\end{array}$ \\
\hline HYD & 100 & 6.0 & 0.0 & 0.0 & 100 & $23-53$ & - \\
\hline NUCL & 34 & 10.0 & 5.6 & 0.2 & 4 & 81 & - \\
\hline $\mathrm{BC}$ & $38-43$ & 7.0 & 2.1 & 0.1 & 8 & 85 & - \\
\hline $\mathrm{HC}$ old & $38-45$ & 6.0 & 2.1 & 0.2 & 30 & 82 & - \\
\hline $\mathrm{CC}$ & $50-60$ & 3.0 & 1.3 & 0.2 & 50 & 92 & - \\
\hline NG ST & $38-45$ & 3.0 & 0.4 & 0.2 & 50 & 92 & - \\
\hline O ST & $38-44$ & 3.0 & 0.4 & 0.2 & 50 & 90 & - \\
\hline O GT & $34-39$ & 3.0 & 0.0 & 0.0 & 100 & 90 & - \\
\hline CC new & 61 & 3.0 & 0.7 & 0.3 & 50 & 92 & 947 \\
\hline NG GT & $36-40$ & 3.0 & 1.3 & 0.2 & 100 & 92 & 510 \\
\hline OIGA Retro & $44-45$ & 3.0 & 0.7 & 0.2 & 100 & 98 & 397 \\
\hline
\end{tabular}

Figure 2: Technical and economic parameters of existing and new power plants in 2024.

Based on information from Eurostat ${ }^{8}$ and $\mathrm{UBA}^{9}$ concerning output of CHP units and respective shares of fuel carriers, we define must-run shares for conventional units differentiated into the summer and winter season that follow the distribution

grid-development-plan-2014-first-draft

${ }^{8}$ Combined Heat and Power (CHP) data 2005-2012,

URL: http://ec.europa.eu/eurostat/web/energy/data

${ }^{9}$ German federal environment agency, URL: www. umweltbundesamt.de/node/12350/ 
of heat degree days over the year 2012 in Germany, i.e. 81 percent of CHP electricity is produced in the winter half year covering the six months from October to March.

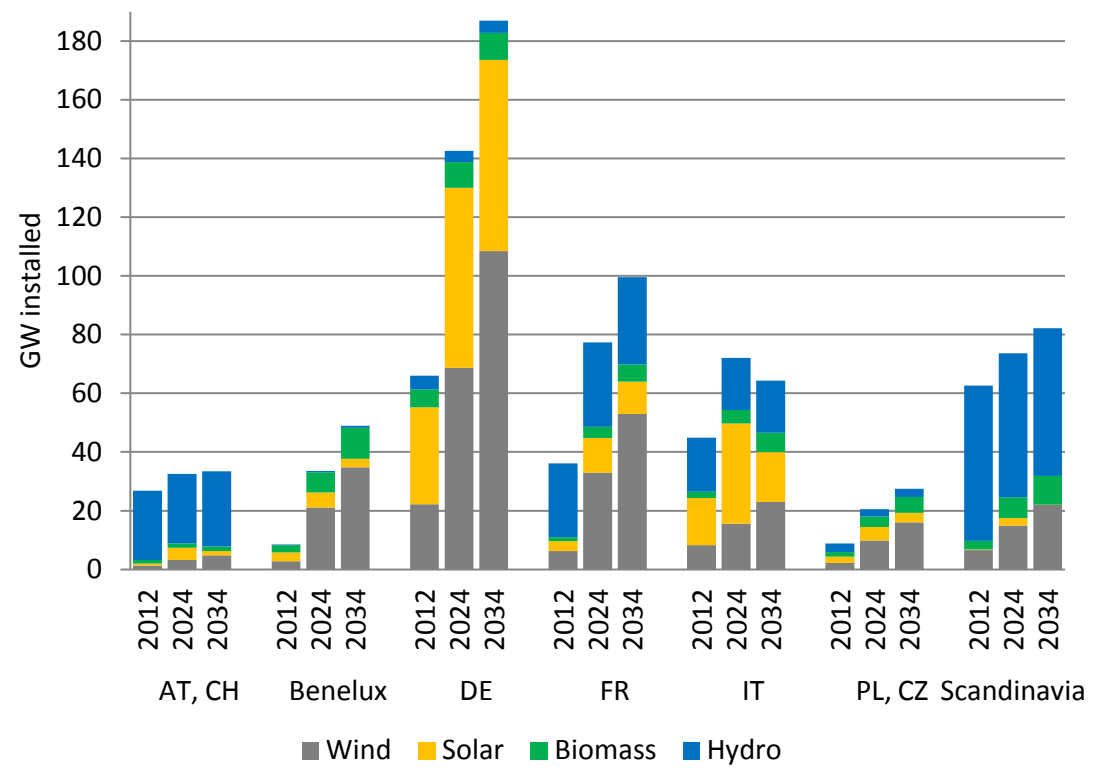

Figure 3: Renewable energy generation capacities in 2012, 2024 and 2034.

The supply side is completed with increasing renewable energy contributions from wind, solar, biomass and hydro power units (see Figure 3). Regarding wind, biomass, and hydro power, the assumed expansion corresponds to the renewable energy action plans of the EU-members (NREAP) ${ }^{10}$ and Norway (Ministry of Petroleum and Energy Norway (2009)), and the supply variant E of the Swiss energy perspectives ${ }^{11}$.

For German PV installations the capacity of the draft German grid development plan (NEP) is assumed. Moreover, the NREAP target values for 2020 have proven to be nonbinding with regard to the development of photovoltaic power. According to statistics of the European Union ${ }^{12}$, the 2020 targets for Photovoltaic electricity have already been surpassed in Austria, Belgium, Czech Republic and Italy in 2012. We thus assume installations of $5.8 \mathrm{GW}$ net generation capacity added annually in the countries considered here, whereof $2.5 \mathrm{GW}$ are erected in Germany. This assumption leads to a photovoltaic plant fleet of $128 \mathrm{GW}$ that generates $122 \mathrm{TWh}$ by 2024. Because of its ambitious energy transition policy, Germany is assumed to be the leading country in total renewable capacity installed by 2024 (142.6 GW) and by $2034(186.9 \mathrm{GW})$. The dominant driver is the intense roll-out of wind power (68.7 GW installed in 2024 and 108.5 GW installed in 2034).

\footnotetext{
${ }^{10}$ Renewable Energy Action Plans, URL: www.ecn.nl/projects/nreap/home/

${ }^{11}$ Swiss Federal Office of Energy, URL: www.bfe.admin.ch/themen/00526/00527/index.html? dossier_id=05024\&lang $=$ de

${ }^{12}$ Eurostat: Primary production of renewable energy by type, URL: http://ec.europa.eu/ eurostat/tgm/table.do?tab=table\&init=1\&plugin=1\&language=en\&pcode=ten 00081
} 
The potential supply profile of renewable energies in the model is seasonally differentiated in case of wind and photovoltaic energy, whereas hydro and biomass power plants are assumed to be capable of a constant electricity provision throughout the year. For the availability of photovoltaic and wind energy we assume daily profiles as experienced in Germany in 2012, and scale these profiles to fit country specific output and its prospected development until 2034. Due to computational effort particularly with regard to ramping processes of power plants integrated with investment decisions, we are confined to the representation of a limited number of load situations. Thus, a year is modeled by four representative days that are chosen to capture the major part of the merit-order effects of wind and photovoltaic energy sources.

While photovoltaic energy fluctuates mostly between seasons, wind power in central Europe is highly volatile within seasons and at the same time generates the dominant share of its yield in winter. Therefore, we distinguish only between summer and winter for PV energy, and more case sensitive for wind energy. We model a strong wind event, a calm wind event and an average wind event for the representation of the winter half-year, whereas the whole summer season is represented by an averaged wind event. The strong wind event is based on the average wind output and averaged daily profile of the 29 days with the strongest wind, the calm wind event on those of the 30 days with weakest wind, while the third winter event is represented by the average of the remaining days in winter. The corresponding frequencies are 8.2 and 7.9 percent for the calm and strong wind events, and 33.9 and 50 percent for the normal winter and summer event respectively.

Furthermore, we adopt fuel price assumptions from the NEP and statistics from the German hard coal branch ${ }^{13}$ for hard coal. However, we use comparatively low $\mathrm{CO}_{2}$ prices of ten Euro by 2024 and 30 Euro per ton by 2034, due to weak medium term perspectives of the emission market. Without a stringent reform of the emission trading system, the respective prices are considered to remain around the current level of seven Euro, and are assumed to reach ten Euro per ton by 2024. The NEP also provides the input for the assumptions regarding the development of German interconnectors to foreign countries. The remaining country connections are reflecting the grid expansion according to the ten year network development plan of the European Union (TYNDP 2014) ${ }^{14}$. In aggregate, these programs lead to more than a doubling of transfer capacities by 2024 compared to 2012 .

Regarding the German renewable energy support, we follow the development of the German average tariffs for solar and biomass electricity as projected by R2b in its prognosis for the German transmission system operators (R2b (2013)) for the year 2017, which we extrapolate linearly until 2024. We assume the following average guaranteed tariffs in Euro per MWh for the installed renewable energy fleet in Germany by 2024 (2034): Wind power 88.2 (70), Photovoltaics 230 (40), Biomass 174 (130) and Hydro 50 (50). By 2034 these average tariffs will fall significantly in correspondence with considerably lower tariffs for plants connected to the grid after

\footnotetext{
${ }^{13}$ Statistics on fuel price developments, URL: www.kohlenstatistik.de/17-0-Deutschland

${ }^{14}$ European Network of Transmission System Operators for Electricity (ENTSO-E), URL: www .entsoe.eu/major-projects/ten-year-network-development-plan/tyndp-2014
} 
2012.

As laid out in the model section above, the demand side is represented by linear demand functions defined by reference prices, consumption quantities and the demand elasticity at the reference points. The reference prices are based on spot market (day ahead) prices for the German-Austrian region at the European Energy Exchange in Leipzig (EEX), whereas consumption data is taken from ENTSO-E ${ }^{15}$. Furthermore, we assume grid losses according to statistics of the international energy agency (IEA) provided by the World Bank ${ }^{16}$ for countries where almost the complete power plant park is represented. However, Italy, Germany, and France have substantial small scale fossil fuel and waste combustion capacities that are not represented and compensate losses. We therefore assume zero losses for Germany and Italy and a two percent loss in France.

\section{Calibration}

The model is calibrated for basic electricity system indicators of the year 2012. Target values are on the one hand the spot market prices at the EEX, and on the other hand the shares of hard coal, and natural gas in the supply mix. Calibration is achieved through elasticities and the adjustment of prices for natural gas and hard coal. While estimations of own-price elasticities of electricity in the literature vary considerably across countries, sectors of the economy and with regard to the considered time interval (long run versus short run), they lie quite generally between 0 and -1 in most assessments. Clearly, for longer time horizons they take on higher values as summarized in (Madlener and Bernstein (2011)). For our long-run equilibrium model calibration we tested elasticities ranging from -0.2 to -0.4 .

The fuel prices for natural gas and hard coal are systematically varied for the initial model period to achieve reasonable values for the country specific use of these fuels ${ }^{17}$ according to the statistics of ENTSO-E ${ }^{18}, \mathrm{BMWi}^{19}$ and $\mathrm{CBS}^{20}$. The fuel prices from a first calibration step are subsequently used in the elasticity calibration that aims at a replication of German wholesale electricity prices, and is in turn followed by a last step of fuel price adjustments.

Figure 1 shows the final calibration results for hard coal and natural gas prices assuming a demand elasticity of -0.3 together with simulated and historic generation

\footnotetext{
${ }^{15}$ Consumption data, URL: www.entsoe.eu/data/data-portal/consumption

${ }^{16}$ Electric power transmission and distribution losses, URL: data.worldbank.org/indicator/EG.ELC.LOSS.ZS/

${ }^{17}$ The chosen target value of electricity from natural gas includes electricity from mixed fossil fuel sources as referenced in the ENTSOE data.

${ }^{18}$ Production Data, URL: www.entsoe.eu/data/data-portal/production

${ }^{19}$ Energy Data document of the German Ministry for Economics, gross electricity generation by fuel transformed to net generation by assumption of about seven percent own consumption, URL: http://bmwi.de/DE/Themen/Energie/Energiedaten-und-analysen/ Energiedaten/gesamtausgabe

${ }^{20}$ Statistics of the Netherlands: annual energy balance sheets, URL: www.cbs.nl/en-GB/menu/themas/industrie-energie/nieuws
} 


\begin{tabular}{|c|c|c|c|c|c|c|}
\hline & \multirow[t]{2}{*}{ Had Coal } & \multirow[t]{2}{*}{ Natural Gas } & \multicolumn{2}{|c|}{ Had Coal } & \multicolumn{2}{|c|}{ Natural Gas } \\
\hline & & & Historic & Model & Historic & Model \\
\hline AT & 13.0 & 21.7 & 4.4 & 2.8 & 9.4 & 8.9 \\
\hline $\mathrm{BE}$ & 12.3 & 20.5 & 2.3 & 2.2 & 22.7 & 26.0 \\
\hline $\mathrm{CH}$ & 11.4 & 33.9 & 0.0 & 0.0 & 0.5 & 0.5 \\
\hline$C Z$ & 11.5 & 9.3 & 4.5 & 3.9 & 7.1 & 6.8 \\
\hline DE & 12.1 & 21.1 & 115.3 & 119.7 & 64.1 & 64.7 \\
\hline DK & 14.6 & 20.0 & 7.6 & 7.7 & 4.2 & 4.3 \\
\hline FR & 11.5 & 22.2 & 17.4 & 17.2 & 24.0 & 24.5 \\
\hline IT & 15.9 & 25.5 & 46.1 & 47.8 & 138.3 & 133.2 \\
\hline Lux & 11.4 & 19.6 & 0.0 & 0.0 & 2.4 & 2.3 \\
\hline NL & 9.4 & 20.6 & 28.0 & 24.6 & 52.0 & 52.8 \\
\hline Nor & 16.8 & 28.6 & 0.0 & 0.0 & 0.0 & 0.0 \\
\hline PL & 11.2 & 19.8 & 79.7 & 77.4 & 4.3 & 3.6 \\
\hline SE & 20.2 & 21.2 & 0.6 & 0.8 & 3.5 & 2.7 \\
\hline
\end{tabular}

Table 1: Calibrated fuel prices for hard coal and natural gas, corresponding simulated electricity generation and their historic values according to statistical information.

based on these fuel carriers. With the exceptions of Switzerland, Italy, and Norway, we find reduced natural gas prices compared to the baseline assumption of 25 Euro per MWh, whereas hard coal prices are only reduced against their baseline value of 11.4 Euro per MWh in case of the Netherlands and, to a minor extent, in Poland. In contrast, in the other countries hard coal prices are increased by up to 77 percent as in the case of Sweden. These adjustments reflect for instance Swedish carbon taxes, and other costs of the utilization of fossil fuels not considered in our baseline assumptions like intra country transport cost and additional taxes.

\begin{tabular}{|c|c|c|c|c|c|c|c|c|}
\hline & \multicolumn{3}{|c|}{ Prices [Euro per MWh] } & \multicolumn{4}{|c|}{ Market Value [Euro per MWh] } \\
\hline & & Spot & Surcharge & Consumer $^{1}$ & Wind & Solar & Biomass & Hydro \\
\hline $\begin{array}{l}\bar{d} \\
\overline{0} \\
\overline{2}\end{array}$ & 2012 & 42.4 & 38.0 & 80.4 & 41.1 & 45.7 & 42.4 & 42.4 \\
\hline 는 & 2012 & 42.6 & $39.8^{2}$ & 82.4 & 37.3 & 44.2 & 42.7 & 42.6 \\
\hline 姜 & 2013 & 37.8 & $47.7^{2}$ & 85.5 & 32.2 & 37.0 & 37.9 & 37.2 \\
\hline
\end{tabular}

${ }^{1}$ Generation related part of consumer prices, i.e. sum of spot price and surcharge.

${ }^{2}$ Estimated ex ante value including ex post catch up in the following year.

Source: EEX, Energy Brainpool (2014), EMELIE-ESY Capmod.

Table 2: Historic values and model simulation (dotted) for German spot (day ahead) prices, renewable energy surcharge and market values of renewables.

Table 2 shows the results of the procedure and highlights the accuracy in regard 
to the replication of factual average German wholesale market prices, the renewable energy surcharge and the market values of the main renewable energy technologies in 2012. The table documents a model deviation from historical spot (day ahead) prices at the European energy exchange (EEX) for the German market region of less than one percent, and a reasonably well reproduction of the renewable energy surcharge $^{21}$ in Germany. By late 2011, the necessary core surcharge for the year 2012 was estimated at 33.1 Euro per MWh, but the following surcharge in 2013 included a catch-up of 6.7 Euro that balances the EEG account ex post. For the comparison we use the aggregated value including the catch-up. It was among other things due to a reduced wholesale electricity price compared to its estimation in 2011 and reflects that the cost-covering surcharge would have been higher.

The comparison of our results with historic market results shows that the value of wind power is overestimated by the simulation, whereas the corresponding figures for the other RES-technologies are simulated more accurately. A reason for the difference in wind market values is given by an extremely low market value for wind of only 60 percent in December. These were due to pronounced negative prices induced by high wind yields particularly over the christmas holidays 2012. Figure 3 demonstrates the seasonal accuracy of the price simulations with our aggregation of demand and wind conditions compared to historic values. While a satisfactory match is reached for less extreme wind conditions, under the strong wind event in winter (below left) simulated prices are significantly above their historic values. These
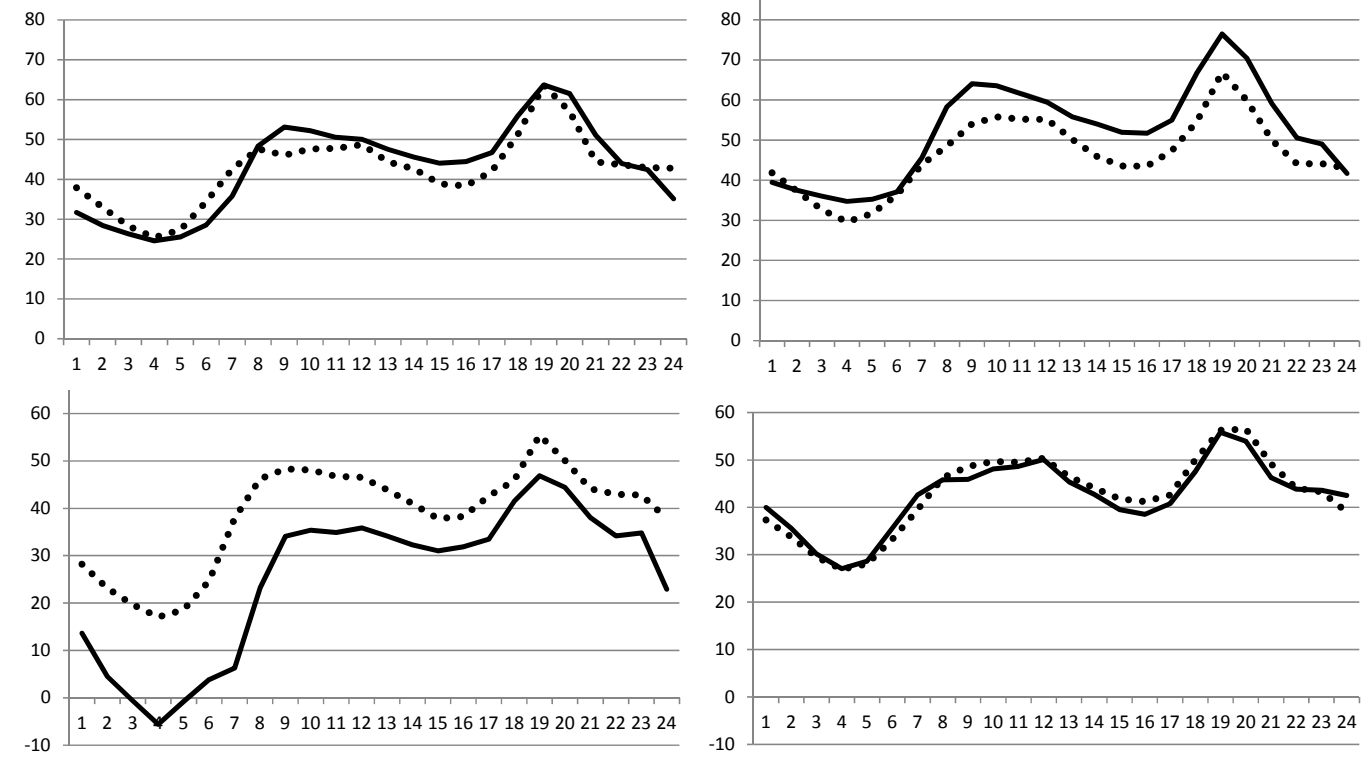

Table 3: Historic values and model simulation for seasonally averaged German dayahead prices under normal winter (top left), calm winter (top right), stormy winter (below left) and summer (below right) over the course of the day.

deviations can in part be explained by our assumption of perfect foresight in the

\footnotetext{
${ }^{21}$ The surcharge calculated here corresponds to the so-called 'core surcharge' that refers to the differential costs divided by non-privileged consumption. The actual levied surcharge includes amongst other things financing costs of a reserve for unexpected market revenue developments.
} 
model. This does not reflect surprisingly low utilization of ramped-up conventional capacity experienced under more accentuated wind events than in our averaged model events. Correspondingly, our market values are not impacted by negative values of wind feed-in at negative wholesale prices and our surcharge is about five percent lower than was actually adequate in 2012 .

However, in the future negative prices will play a minor role, since the renewables in-feed at hours of negative spot prices will be discouraged by a reform of the support system in $2015^{22}$. This will ceteris paribus lead to higher market values that are less inflated by negative energy revenues and, therefore, correspond more closely to our simulation.
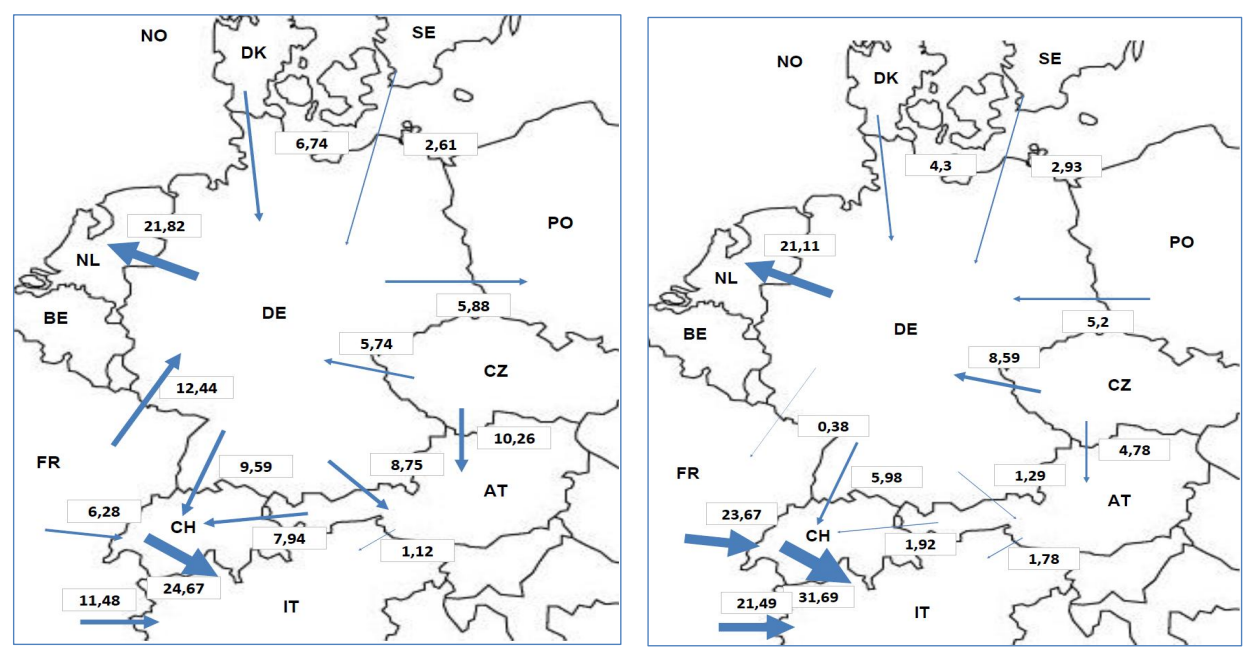

Figure 4: Factual net electricity exports (ENTSO-E) and model simulation for 2012 in TWh.

Our calibration results are also reflected in the electricity trade between member states. Figure 4 shows factual net electricity export in central Europe together with our model results and shows that the model replicates annual flows with fair accuracy. Clearly, the model does not account for cross border loop flows so that electricity transits are underestimated. For instance, the model shows large direct flows from France to Switzerland, while in reality some of these trades flowed via Germany, which can be detected by larger corresponding arrows from France to Germany and from Germany to Switzerland on the left hand side of Figure 4.

\footnotetext{
${ }^{22}$ EEG 2014; See also Connect (2014)
} 


\section{Results}

We model three scenarios with varying flexibility of the supply side and two policy settings each. Scenario 'Rigid' assumes a price inelastic renewable energy in-feed and a CHP electricity supply that matches at least exogenously given heat consumption. Scenario 'RES Flex' allows a partial curtailment of wind energy to reduce supply when market prices are below zero or do not cover the costs of capacity payments. The full flexible scenario 'Flex' additionally assumes flexible CHP with a utilization that is not bound to heat demand.

For these three scenarios, we simulate two policies. In the 'EOM' setting the policy follows an energy-only market approach, whereas 'CM' represents a capacity market policy based on the obligation of suppliers to hold reliable capacities in excess of peak supply. This is essentially an ideal type of certificate trading system with no market frictions as described in Traber (2014). Here the value of renewables contains the payments for purchasing reliability certificates in addition to market prices. Altogether, we simulate six combinations of policies and supply scenarios. Table 4 summarizes the results in regard to spot prices, the surcharge, capacity prices, and market values of RES-technologies in Germany by 2024 .

\begin{tabular}{|c|c|c|c|c|c|c|c|c|c|}
\hline \multirow{2}{*}{\multicolumn{2}{|c|}{2024}} & \multicolumn{4}{|c|}{ Prices [Euro per MWh] } & \multicolumn{4}{|c|}{ Market Value [Euro per MWh] } \\
\hline & & Spot & Surcharge & Consumer* & Capacity & Wind & Solar & Biomass & Hydro \\
\hline \multirow{3}{*}{$\sum_{\text {O }}$} & Rigid & 36.7 & 61.6 & 98.2 & - & 31.8 & 39.3 & 36.7 & 36.7 \\
\hline & RES Flex & 36.9 & 61.3 & 98.2 & - & 32.4 & 39.3 & 36.9 & 36.9 \\
\hline & Flex & 40.0 & 59.1 & 99.1 & - & 36.9 & 41.5 & 40.0 & 40.0 \\
\hline \multirow{3}{*}{$\sum_{\cup}$} & Rigid & 36.2 & 72.3 & 108.4 & 5.6 & 14.7 & 29.1 & 35.9 & 35.9 \\
\hline & RES Flex & 40.6 & 64.6 & 105.2 & 5.6 & 29.3 & 36.8 & 40.3 & 40.3 \\
\hline & Flex & 44.5 & 62.0 & 106.5 & 5.3 & 34.5 & 39.6 & 44.3 & 44.3 \\
\hline
\end{tabular}

*Generation related part of consumer prices, i.e. sum of spot price and surcharge.

Source: EMELIE-ESY Capmod.

Table 4: Results for prices and values of renewable technologies compared to average market prices in Germany in 2024.

The outcome for scenarios with EOM regulation is shown in the first three rows. We find electricity spot prices of around 37 Euro per MWh, which is a ten percent reduction compared to 2012 if not the full supply flexibility is assumed, i.e. in scenarios Rigid and RES Flex under EOM policy. A major part of this decrease has almost been experienced by 2013 with average EEX spot prices of 37.8 Euro per MWh. Flexibility of CHP power combined with a revenue maximizing operation of wind power leads to prices of 40 Euro per MWh, as indicated by row EOM Flex. The surcharge values for 2024 range under EOM policy from about 59 to 62 Euro per MWh. Compared to the 2013 full cost core surcharge of 47.7 Euro per MWh, this corresponds to a comparatively modest increase of roughly 25 to 30 percent in 
light of more than a doubling of renewable electricity.

Moreover, flexibility reduces the necessary surcharge by about five percent as is evident from comparison of the rows in the second column of Table 4. Flexibility dampens the necessary surcharge for two reasons. Firstly, electricity spot prices increase, and secondly the relative market value particularly of wind power is improved. Both factors lead to a reduced difference between spot prices and guaranteed feed-in tariffs. Furthermore, the generation related part of consumer prices are shown in the third row of Table 4 and vary only by less than two percent between the scenarios.

A capacity market increases consumer prices by up to ten percent against the EOM setting as is obtained from comparison of the respective column in Table 4. In the scenario Rigid, the dominant part of this effect on consumer prices is channeled via the surcharge, which is increased by about 11 Euro per MWh or 17 percent compared to the EOM setting. This corresponds in total to a 51 percent increase of the surcharge compared to its respective value in 2013 . In the flexible scenarios, the spot market becomes the more important channel with spot price increases of up to 11 percent of the corresponding EOM values (column spot prices of Table 4) due to the introduction of a capacity market. However, in the more flexible scenarios the effect of the capacity mechanism on the generation related part of the consumer price is limited to a little more than seven percent.

For all scenarios, imposing a capacity mechanism triggers a drastic reduction of market values of wind and solar power. Even increases of spot prices due to the capacity mechanism does not lead to higher revenues for renewable energy. Under a rigid supply structure, the market value of wind energy supplies by 2024 is with around 15 Euro per MWh only a little above 40 percent of the average market price (row CM Rigid, column surcharge of Table 4 ). A market oriented wind energy utilization would improve the value of wind to about 30 Euro per MWh and a market value factor of above 70 percent even under a capacity market regime. The dependence of these results on the supply scenario can be explained by two interacting facts that are crucial in the rigid setting. First, wind and solar power have large potentials in those hours when the capacity reserve mechanism is binding, i.e. in the simulated situation of stormy wind conditions particularly around noon. Under our model assumptions, wind and solar provide up to 67 GW of electricity generation which frequently leads to pronounced negative market values net of reserve payments. Second, the renewable energy supplies enjoy priority dispatch and are not partially curbed even in cases when their over all market value including reserve provision costs is negative.

Assuming fully flexible electricity supply stabilizes the market perspectives for the year 2024 as can be seen from spot prices in rows Flex 2024 and CM Flex 2024. Comparing with the market situation in 2012, spot price decrease only insignificantly by six percent if no capacity mechanism is introduced, and increase by about five percent under a capacity market regime. Moreover, market values of renewable energy are comparatively stable when compared to the assumption of inflexible $\mathrm{CHP}$ and renewable energy supply. In particular, wind power market values gain to 
a major extent by the introduction of flexibility. Moreover, the potential negative effects of the introduction of a capacity mechanism are partially mitigated, as is evident by comparison of the rows EOM and CM in the flexible setting. Consequently, the effect of the introduction of a capacity mechanism on the surcharge is less pronounced and amounts to only about five percent or less than three Euro.

However, throughout the scenarios price induced consumer reactions are small so that the basis for the surcharge payments does not change significantly: German electricity consumption varies in 2024 only between 547 and 550 TWh for the different EOM-Scenarios. Due to the price increases induced by a capacity mechanism we find additional demand reductions of a little more than two percent resulting in consumption of between 535 and 539 TWh.

For the simulation of 2034, we assume full flexibility of the supply side for all scenarios, i.e. market based renewable energy provision and flexible CHP output, and simulate EOM and CM policy. Table 5 shows the perspectives for spot market prices, renewable energy surcharge, consumer and capacity prices as well as market values of RES-technologies in Germany by 2034 given the scenario of flexible supply for all model periods.

\begin{tabular}{|c|c|c|c|c|c|c|c|c|}
\hline \multirow{2}{*}{2034} & \multicolumn{4}{|c|}{ Prices [Euro per MWh] } & \multicolumn{4}{|c|}{ Market Value [Euro per MWh] } \\
\hline & Spot & Surcharge & Consumer* & Capacity & Wind & Solar & Biomass & Hydro \\
\hline$\sum_{\text {O }}$ & 56.9 & 18.5 & 75.4 & - & 49.0 & 61.6 & 56.9 & 56.9 \\
\hline$\sum_{u}$ & 59.3 & 22.5 & 81.7 & 4.2 & 44.5 & 59.7 & 59.1 & 59.1 \\
\hline
\end{tabular}

*Generation related part of consumer prices, i.e. sum of spot price and surcharge.

Source: EMELIE-ESY Capmod.

Table 5: Results for prices and values of renewable technologies compared to average market prices in Germany in 2034.

In the setting of EOM policy, we find electricity prices of about 57 Euro per MWh shown in the first row of Table 5, which correspond to an about 40 percent increase compared to 2024. This increase is due to a major decommission of plants in the thermal power sector and corresponding frequent scarcity pricing of electricity. In comparison to 2024, the surcharge values for 2034 under EOM policy reduces drastically, namely by about 70 percent. The dominant driver of this result is the reduction of feed-in tariffs guaranteed by the German government following the year 2012, which leads to a substantial fall in average tariffs. At the same time, spot prices and market values of RES-technologies increase which, in turn, leads to reduced differential costs per unit: The market values of wind gain by about a third compared to the flexible scenario in 2024, and are simulated to be 49 Euro per MWh. Increases of market values for the other renewables are even more pronounced and exceed the wholesale price growth in case of solar power. 
Although the supported energy increases by another 36 percent compared to 2024, the volume effect is widely overcompensated by reduced fixed payments and increased market values such that average extra costs decrease. Furthermore, the reduction of the renewable energy surcharge dominates the price increase on the spot market such that consumer prices fall by almost a quarter compared to 2024 in the EOM scenario.

By 2034, the introduction of a capacity market increases consumer prices by more than eight percent as can be seen from Table 5 by comparison with the EOM setting. The main driver of this result is the impact on the surcharge, which increases by 21 percent or four Euro per MWh due to the capacity mechanism. By contrast, spot prices are increased due to the capacity market by only four percent or 2.4 Euro per MWh, which is almost 50 percent less than in 2024 under the same flexibility conditions. An explanation is that in the period from 2024 to 2034 sufficient gas fired capacities will be available for retrofit, which provides a comparatively cheap source of reliability. Therefore, the capacity prices are reduced from more than five to about four Euro per MWh.

\section{Conclusion}

This article uses a market equilibrium model of the central European electricity system to analyze perspectives of the surcharge levied on German consumers to finance the renewable energy support. Three scenarios that assume different responsiveness of supply to price signals are investigated under two market design settings: a energy-only paradigm and a capacity market regime.

It turns out that the surcharge development depends on the flexibility of supply and on the market design. Establishing a price oriented utilization of renewable energy, and a flexible CHP electricity supply in a energy-only market system results only in comparably minor surcharge increases by 2024. Under these conditions, doubling of the renewable energy share to more than 50 percent by 2024 leads to an increase of the surcharge of less than a fourth, i.e. 24 percent compared to 2013. By contrast, rigid supplies of RES and CHP power in a capacity market regime lead to a substantial growth of the core surcharge of 51 percent.

The main driver of our result is a highly sensitive market value of wind, and, less pronounced, solar power. Both, wind and solar power can stabilize its market values around today's in a flexible supply framework under the current market regime. By contrast, wind power is threatened to loose more than half and solar power a quarter of their market values under a rigid supply structure combined with a capacity market. This increases the cost differential between guaranteed tariffs for these technologies and, hence, the surcharge. As a secondary effect, consumption is reduced by the implied consumer price growth, which in turn accelerates the rise of necessary surcharge per consumed electricity.

On the background of the German attempt to better integrate renewable energy into the electricity system and to introduce a more market oriented support, our 
findings call for a timely activation of flexibility potentials. Furthermore, a clear commitment to the energy market framework is necessary to stabilize the expectation of future revenues of wind and solar power investments.

The model opens up several options for future research. Given the results found in this paper, promising subjects are the assessment of a dynamic reallocation of surcharges. These could be used to either approach the problem of potentially insufficient investment in reliable capacity or the alignment of $\mathrm{CO}_{2}$ reduction with the renewable energy development in Germany. 


\section{Notation}

\begin{tabular}{|c|c|}
\hline Sets & \\
\hline$Y$ & set of time periods, where $y$ denotes a single period, i.e. $2012,2024,2034$ \\
\hline$N$ & set of technologies, where $n$ denotes a single technology \\
\hline & and $n^{*}$ denotes technologies from the subset of renewable energies \\
\hline$T$ & set of time steps, where $t$ denotes a single time step, i.e. $\mathrm{t}=1, \ldots, 24$ \\
\hline$\Omega$ & set of events, where $\omega$ denotes a single event \\
\hline$S$ & set of regions, where $s$ denotes a single region \\
\hline Variables & \\
\hline$P$ & price \\
\hline$X$ & electricity consumption \\
\hline$q$ & electricity production \\
\hline$k$ & power plant investment \\
\hline$l$ & ramping \\
\hline$\lambda$ & shadow variable for maximum load gradients \\
\hline$\rho$ & shadow variable for minimum ramping requirements \\
\hline$\kappa$ & shadow variable for maximum generation capacity \\
\hline$\iota$ & shadow variable for investment restriction \\
\hline$\tau$ & shadow variable for transmission capacity \\
\hline$\mu$ & shadow variable for reserve obligation, i.e. capacity certificate price \\
\hline$E x$ & export of electricity \\
\hline$\xi$ & surcharge \\
\hline Parameters & \\
\hline$F$ & investment costs \\
\hline$\delta$ & discount rate \\
\hline$C_{q}$ & variable generation costs \\
\hline$C_{l}$ & costs of ramp-up \\
\hline$a$ & plant availability \\
\hline$d$ & ramp-up related depreciation \\
\hline$e$ & specific fuel emission \\
\hline $\bar{l}$ & maximum relative load gradient \\
\hline$O C$ & unit operation and maintenance costs \\
\hline$p f$ & periodic fuel price \\
\hline$r f$ & ramp-up related fuel requirement \\
\hline$\eta$ & degree of efficiency \\
\hline$\phi$ & price of carbon dioxide emissions \\
\hline$f$ & frequency of events \\
\hline$\epsilon$ & price elasticity of demand \\
\hline$k_{0}$ & existing capacity \\
\hline$X 0$ & reference consumption \\
\hline$P 0$ & reference price \\
\hline$\xi_{0}$ & reference surcharge \\
\hline $\bar{\alpha}$ & required firm capacity factor \\
\hline $\bar{a}$ & firm availability factor \\
\hline $\bar{\beta}$ & share of non-priviliged consumption \\
\hline$\zeta$ & fixed feed-in tariff \\
\hline
\end{tabular}




\section{References}

Bode, S. and H.-M. Groscurth (2006). Zur Wirkung des EEG auf den Strompreis. HWWA Discussion Papers 348, Hamburg Institute of International Economics (HWWA).

Bushnell, J. (2010). Building blocks: Investment in renewable and non-renewable technologies. Harnessing Renewable Energy in Electric Power Systems: Theory, Practice, Policy, 159.

Connect (2014). Leitstudie Strommarkt - Arbeitspaket Optimierung des Strommarktdesigns. Technical report, Bundesministerium für Wirtschaft und Energie.

Egerer, J., C. Gerbaulet, R. Ihlenburg, F. Kunz, B. Reinhard, C. v. Hirschhausen, A. Weber, and J. Weibezahn (2014). Electricity Sector Data for Policy-Relevant Modeling - Data Documentation and Applications to the German and European Electricity Markets. Data Documentation, DIW 72, Deutsches Institut für Wirtschaftsforschung.

Energy Brainpool (2014). Ermittlung des Marktwertes der deutschlandweiten Stromerzeugung aus regenerativen Kraftwerken für das Jahr 2015. Endbericht, Studie für die vier deutschen Übertragungsnetzbetreiber im Auftrag der TenneT TSO GmbH.

Fürsch, M., R. Malischek, and D. Lindenberger (2012). Der Merit-Order-Effekt der erneuerbaren Energien - Analyse der kurzen und langen Frist. EWI Working Papers, Energiewirtschaftliches Institut an der Universität zu Köln.

Hirth, L. (2013). The market value of variable renewables: The effect of solar wind power variability on their relative price. Energy Economics 38, 218-236.

Jonsson, T., P. Pinson, and H. Madsen (2010). On the market impact of wind energy forecasts. Energy Economics 32(2), 313 - 320.

Madlener, R. and R. Bernstein (2011). Responsiveness of Residential Electricity Demand in OECD countries - A Panel Cointegation and Causality Analysis. FCN Working Paper 8/2011, Institute for Future Energy Consumer Needs and Behavior.

Ministry of Petroleum and Energy Norway (2009). National Renewable Energy Action Plan under Directive 2009/28/EC.

Munksgaard, J. and P. E. Morthorst (2008). Wind power in the Danish liberalised power market - Policy measures, price impact and investor incentives. Energy Policy 36(10), 3940-3947.

Nicolosi, M. (2012). The economics of renewable electricity market integration. An empirical and model-based analysis of regulatory frameworks and their impacts on the power market. Ph. D. thesis, University of Cologne. 
O'Mahoney, A. and E. Denny (2011). The merit order effect of wind generation on the irish electricity market. MPRA Paper 56043, University Library of Munich.

R2b (2013). Jahresprognose 2014 und Mittelfristprognose bis 2018 zur deutschlandweiten Stromerzeugung aus EEG geförderten Kraftwerken. Technical report, 50Hertz Transmission $\mathrm{GmbH}$ and Amprion GmbH and TenneT TSO GmbH and TransnetBW GmbH.

Rathmann, M. (2007). Do support systems for res-e reduce eu-ets-driven electricity prices? Energy Policy 35(1), 342-349.

Schröder, A., F. Kunz, J. Meiss, R. Mendelevitch, and C. v. Hirschhausen (2013). Current and prospective costs of electricity generation until 2050. Data Documentation, DIW 68, Deutsches Institut für Wirtschaftsforschung (DIW), Berlin.

Sensfuß, F., M. Ragwitz, and M. Genoese (2008). The merit-order effect: A detailed analysis of the price effect of renewable electricity generation on spot market prices in Germany. Energy Policy 36 (8), 3086 - 3094.

Traber, T. (2014). Capacity Mechanisms on Central European Electricity Markets - Effects on Consumers, Producers and Technologies until 2033. Discussion Papers, DIW 1385, Deutsches Institut für Wirtschaftsforschung (DIW), Berlin.

Traber, T. and C. Kemfert (2009). Impacts of the German Support for Renewable Energy on Electricity Prices, Emissions, and Firms. The Energy Journal 30(3), $155-178$.

Traber, T. and C. Kemfert (2011). Gone with the wind? - electricity market prices and incentives to invest in thermal power plants under increasing wind energy supply. Energy Economics 33(2), 249-256. 